\title{
Driving cancer through ErbB3
}

\section{By Kai-Jye Lou, Senior Writer}

Roche's Genentech Inc. unit has shown that mutations in ERBB3 can drive oncogenesis by enhancing the receptor's ability to form a heterodimer with HER2. ${ }^{1}$ Because the process appears to depend on HER2, the results suggest existing HER2-targeted therapies could also be effective in cancers driven by mutations in ERBB3.

Epidermal growth factor receptor 3 (EGFR3; HER3; ErbB3) is a member of the ErbB family of receptor tyrosine kinases. The membrane-bound receptor is comprised of an extracellular domain (where ligand binding and dimerization interactions occur), an $\alpha$-helical transmembrane segment and an intracellular tyrosine kinase domain to phosphorylate downstream targets.

Unlike other members of the ErbB family, ErbB3's kinase domain is impaired and does not show significant kinase activity on its own. ${ }^{2}$ To activate downstream cellular signaling pathways via phosphorylation, a ligand such as neuregulin 1 (NRG1) must first bind to ErbB3's extracellular domain. $^{3}$

"We sought to find out why cancer patients still accumulate recurrent somatic mutations in $E R B B 3$ when the protein is not able to phosphorylate and activate downstream targets on its own." -Somasekar Seshagiri, Genentech Inc.
This ligand binding promotes the formation of a heterodimer between ErbB3 and other members of the ErbB family, such as HER2 (EGFR2; ErbB2; neu), which have functional kinase domains. ${ }^{4,5}$

"We noticed that there were recurrent mutations in ERBB3 in the context of colon and gastric cancers, although the functional relevance of such mutations was unclear," said Somasekar Seshagiri, a principal scientist in molecular biology at Genentech. "We were especially curious about these mutations in $E R B B 3$, as it is the only member of the ErbB family that by itself does not show significant kinase activity. Thus, we sought to find out why cancer patients still accumulate recurrent somatic mutations in $E R B B 3$ when the protein is not able to phosphorylate and activate downstream targets on its own."

Now, Seshagiri's group has characterized the functional relevance of protein-altering somatic mutations in ERBB3 and also assessed the frequency of such mutations across a range of cancers.

Whole-exome sequencing of 507 human primary tumor samples covering 20 types of cancer found ERBB3 mutations in $12 \%$ of gastric cancer samples, $11 \%$ of colon cancer samples and occurring sporadically in samples of other cancer types. The majority of the mutations occurred in the receptor's extracellular domain.
In mouse and human cell lines, most of the cancer-associated ErbB3 mutants tested by the group promoted oncogenic transformation and signaling but only when co-expressed with functional HER2. In cells that expressed mutant ErbB3, antibody-mediated neutralization of NRG1 did not significantly affect cell survival or impair the mutant receptor's ability to form a heterodimer with HER2.

The latter result suggests that oncogenic mutations in the receptor enhance its ability to dimerize with HER2 independently of its ligand (see Figure 1, "Model of oncogenesis driven by mutant ErbB3").

In a mouse model for Erbb3-mutant murine leukemia, mAbs such as MEHD7945A or the anti-HER2 mAb Herceptin trastuzumab, which inhibit ErbB3 signaling, decreased disease severity and increased survival compared with a control $\mathrm{mAb}$.

Results were published in Cancer Cell.

Genentech markets Herceptin to treat HER2-overexpressing breast cancer and HER2-overexpressing metastatic gastric or gastroesophageal junction denocarcinomas.

The company's MEHD7945A, a humanized IgG1 mAb targeting ErbB3 and the closely related EGFR, is in Phase II testing to treat metastatic colorectal cancer or metastatic squamous cell carcinomas of the head and neck. The mAb is also in Phase I testing to treat metastatic epithelial tumors.

"Our hypothesis is that these somatic mutations that accumulate in ERBB3 shift the protein towards an active conformation that enhances its ability to cooperate with HER2," said Seshagiri, the corresponding author. "We believe these mutations tend to make ErbB3 ligand-independent in that the protein no longer needs its ligand to bind to form a heterodimer with HER2."

"This work is interesting, as it shows that a protein that is generally considered to be inactive on its own can acquire mutations that allow it to promote oncogenesis," said Heidi Greulich, an instructor in medicine at the Dana-Farber Cancer Institute and a visiting scientist at the Broad Institute of MIT and Harvard.

"At Merrimack, we are developing ErbB3-directed drugs that primarily target ligand-dependent mechanisms, which have previously been shown to play a prominent role in mediating resistance to both targeted therapy and chemotherapy," said Gavin MacBeath, cofounder and VP of translational research at Merrimack Pharmaceuticals Inc.

"These results now show that mutated ErbB3 may also play a role in cancer. This suggests that as ErbB3-directed drugs are developed clinically, it may be important not only to detect ligand-driven signaling in patient tumors but also identify any mutations that are driving ErbB3 signaling in a ligandindependent manner."

Previously, the rationale for targeting ErbB3 in cancer primarily stemmed from studies linking increased expression of the receptor or NRG1 to resistance against tyrosine kinase inhibitors and chemotherapy ${ }^{6-8}$

The new data further support the case for targeting ErbB3 in cancer and also suggest that patients who have cancers driven by mutations in ERBB3 could potentially benefit from treatment with existing HER2-targeted drugs (see Table 1, “Targeted therapies against HER2 and ErbB3”). 
I Wild-type ErbB3 Ligand present

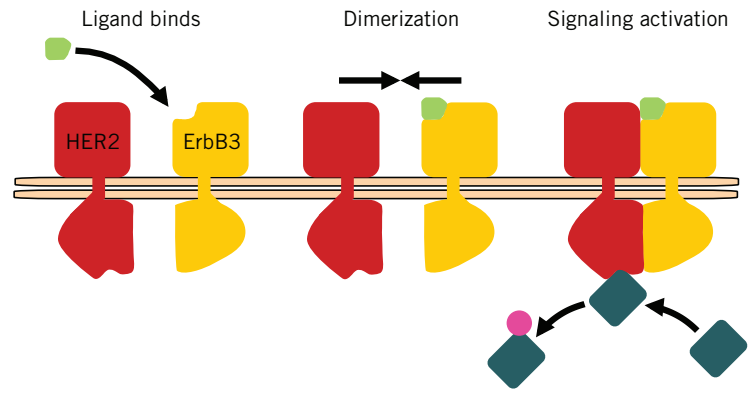

II Wild-type ErbB3

Ligand removed

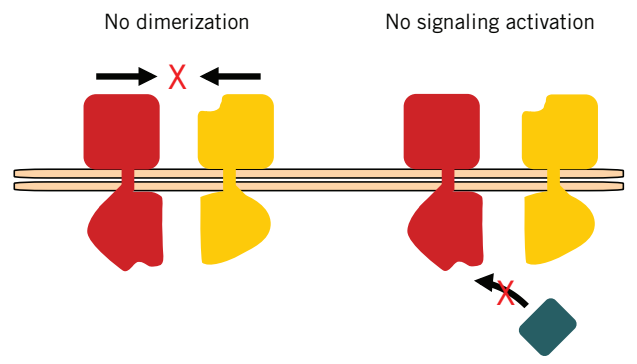

III Mutant ErbB3

Ligand removed

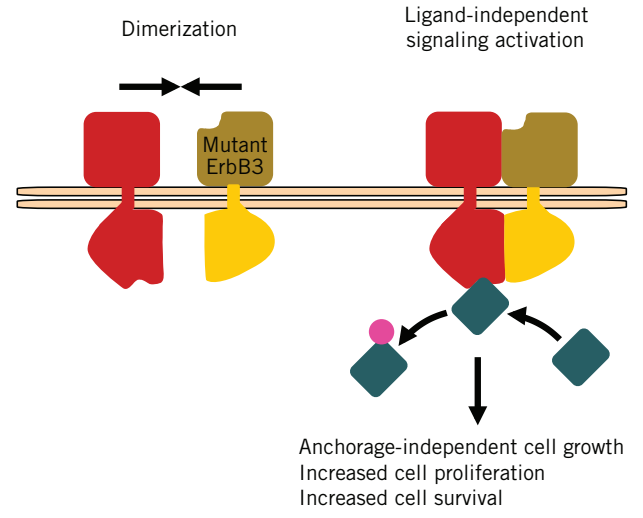

"The most important potential translational aspect of this work is in showing that it may be possible to expand the use of existing HER2targeted therapies into cancer patients who have oncogenic ERBB3 mutations," Greulich told SciBX.

Merrimack has three antibody therapies in clinical development that target ErbB3. MM-121 is being developed with Sanofi and is a human $\mathrm{mAb}$ against ErbB3 in multiple Phase II trials in patients who have breast, ovarian or non-small cell lung cancers (NSCLCs). MM-111, a bispecific antibody that targets ErbB3 and HER2, is in Phase II testing to treat gastric cancers. MM-141, a tetravalent antibody that targets insulin-like growth factor-1 receptor (IGF1R; CD221) and ErbB3, is in a Phase I trial in patients who have advanced solid tumors.

\section{Taking functional insights to the clinic}

Seshagiri said the group at Genentech is now trying to further flesh out the mechanisms by which mutations in ERBB3 drive oncogenesis. To
Figure 1. Model of oncogenesis driven by mutant ErbB3. Epidermal growth factor receptor 3 (EGFR3; HER3; ErbB3) is a receptor tyrosine kinase that is ineffective at activating downstream cellular signaling pathways by itself owing to its impaired kinase domain. Instead, downstream signaling via ErbB3 depends on the binding of an appropriate ligand to the receptor. As reported in Jaiswal et al., oncogenic mutations in $E R B B 3$ are primarily found in the receptor's extracellular domain and render the protein ligandindependent. Binding of a ligand to the wild-type ErbB3 receptor (I) promotes its ability to undergo dimerization with HER2 (EGFR2; ErbB2; neu), which has an active kinase domain. The resulting HER2-ErbB3 heterodimer can then activate downstream signaling pathways. Without an appropriate ligand (II), wild-type ErbB3 is unable to form a heterodimer with HER2 and activate downstream signaling pathways in an effective manner. Oncogenic mutant ErbB3 can form a heterodimer with HER2 in the absence of an appropriate ligand (III) and activate downstream signaling pathways. Addition of an ErbB3 ligand can further stimulate this activity.

help with this, the researchers are looking into generating additional structural information on the target.

"We are also considering the creation of mouse models that will help us better understand at what stage of disease mutant ErbB3 contributes to tumorigenesis," he said.

Seshagiri noted that such models also could provide the opportunity to do some preclinical testing of product candidates being developed at Genentech but declined to disclose details. Seshagiri added it will be important to do follow-up studies in samples from larger patient cohorts to establish the baseline frequency of oncogenic mutations in ERBB3.

"Looking at additional clinical samples could help better determine the prognostic value of these mutations and also could help better predict how tumors with such mutations would respond to a particular treatment," he told SciBX. "Once you have obtained such "The most important
potential translational
aspect of this work is in
showing that it may be
possible to expand the
use of existing HER2-
targeted therapies into
cancer patients who
have oncogenic ERBB3
mutations."
Dana-Farber Cancer Institute information, then you may be able to incorporate the mutational status of $E R B B 3$ into the design of a clinical trial.

"The picture that is emerging is that some tumors may be driven by ligand-dependent ErbB3 signaling in the absence of mutations, while others may be driven by oncogenic mutations, either in the presence or absence of ligands," added MacBeath. "As such, a comprehensive biomarker strategy for ErbB3-directed drugs may require detecting both of these mechanisms."

Greulich thinks it will be important to identify additional ErbB3mutant cancer cell lines and determine how they respond to HER2 inhibition. She said such studies will help determine how useful current HER2-targeted therapies could be against ErbB3-mutant tumors. 
Table 1. Targeted therapies against HER2 and ErbB3. In Jaiswal et al., researchers report data suggesting that cancers driven by oncogenic mutations in epidermal growth factor receptor 3 (EGFR3; HER3; ErbB3) could respond to existing therapies against HER2 (EGFR2; ErbB2; neu). The data also further support the idea of developing ErbB3-targeting therapies to treat cancer. There are at least four HER2-targeting therapies marketed to treat various types of cancer with another five in late-stage clinical development or under regulatory review. The most advanced

ErbB3-targeting therapies are in Phase II testing.

Source: $\mathrm{BCIQ}$; BioCentury Archives

\section{Company}

Product

Description

Latest

stage of

development

Marketed and late-stage therapies that target HER2

Genentech Inc. / Chugai Pharmaceutical Co. Ltd.

(Tokyo:4519) / Roche (SIX:ROG; OTCQX:RHHBY)

Genentech Inc. / Chugai Pharmaceutical Co. Ltd. / Roche Perjeta pertuzumab

Humanized $\mathrm{mAb}$ against HER2

Marketed

Humanized $m A b$ HER dimerization inhibitor that prevents HER2 from binding to other HER receptors (EGFR, ErbB3 and ErbB4)

\begin{tabular}{|c|c|c|c|}
\hline $\begin{array}{l}\text { Genentech Inc. / Chugai Pharmaceutical Co. Ltd. / } \\
\text { ImmunoGen Inc. (NASDAQ:IMGN) / Roche }\end{array}$ & $\begin{array}{l}\text { Kadcyla ado-trastuzumab } \\
\text { emtansine }\end{array}$ & $\begin{array}{l}\text { Humanized } \mathrm{mAb} \text { against HER2 linked to } \\
\text { ImmunoGen's DM1 cytotoxic agent }\end{array}$ & Marketed \\
\hline $\begin{array}{l}\text { GlaxoSmithKline plc (LSE:GSK; NYSE:GSK) / } \\
\text { Eddingpharm Inc. }\end{array}$ & Tykerb lapatinib & $\begin{array}{l}\text { Small molecule EGFR and HER2 receptor kinase } \\
\text { inhibitor }\end{array}$ & Marketed \\
\hline Boehringer Ingelheim GmbH & Tomtovok afatinib & $\begin{array}{l}\text { Small molecule dual inhibitor of EGFR, HER2 and } \\
\text { ErbB4 (HER4) }\end{array}$ & Registration \\
\hline $\begin{array}{l}\text { Biocon Ltd. (NSE:BIOCON; BSE:BIOCON) / } \\
\text { Mylan Inc. (NASDAQ:MYL) }\end{array}$ & Biosimilar trastuzumab & Humanized $\mathrm{mAb}$ against HER2 & Phase III \\
\hline $\begin{array}{l}\text { Celltrion Inc. (KOSDAQ:068270) / } \\
\text { Nippon Kayaku Co. Ltd. (Tokyo:4272) }\end{array}$ & CT-P6 & Humanized $\mathrm{mAb}$ against HER2 & Phase III \\
\hline Pfizer Inc. (NYSE:PFE) / SFJ Pharmaceuticals Inc. & Dacomitinib & $\begin{array}{l}\text { Small molecule inhibitor of human EGFR, HER2 } \\
\text { and ErbB4 }\end{array}$ & Phase III \\
\hline $\begin{array}{l}\text { Symphony Evolution Inc. / Exelixis Inc. } \\
\text { (NASDAQ:EXEL) / Kadmon Corp. LLC }\end{array}$ & XL647; KD019 & $\begin{array}{l}\text { Spectrum selective small molecule inhibitor of } \\
\text { EGFR, HER2 and VEGF }\end{array}$ & Phase III \\
\hline \multicolumn{4}{|l|}{ Clinical-stage therapies that target ErbB3 } \\
\hline Genentech Inc. / Roche & MEHD7945A & Humanized IgG1 mAb targeting EGFR and ErbB3 & Phase II \\
\hline $\begin{array}{l}\text { Merrimack Pharmaceuticals Inc. (NASDAQ:MACK) / } \\
\text { Sanofi (Euronext:SAN; NYSE:SNY) }\end{array}$ & MM-121 & Human mAb against ErbB3 & Phase II \\
\hline Merrimack Pharmaceuticals Inc. & MM-111 & Bispecific antibody targeting HER2 and ErbB3 & Phase II \\
\hline $\begin{array}{l}\text { Daiichi Sankyo Co. Ltd. (Tokyo:4568; Osaka:4568) / } \\
\text { Amgen Inc. (NASDAQ:AMGN) }\end{array}$ & U3-1287, AMG 888 & Human $\mathrm{mAb}$ against ErbB3 & Phase I/II \\
\hline Aveo Pharmaceuticals Inc. (NASDAQ:AVEO) & AV-203 & ErbB3-targeted antibody & Phase I \\
\hline Merrimack Pharmaceuticals Inc. & MM-141 & $\begin{array}{l}\text { Tetravalent antibody targeting insulin-like growth } \\
\text { factor } 1 \text { receptor (IGF1R; CD221) and ErbB3 }\end{array}$ & Phase I \\
\hline $\begin{array}{l}\text { Novartis AG (NYSE:NVS; SIX:NOVN) / } \\
\text { MorphoSys AG (Xetra:MOR; Pink:MPSYF) }\end{array}$ & LJM716 & Human HuCAL antibody against ErbB3 & Phase I \\
\hline Regeneron Pharmaceuticals Inc. (NASDAQ:REGN) & REGN1400 & Human ErbB3 antibody & Phase I \\
\hline Roche & RG7116 & Anti-HER3/ADCC mAb & Phase I \\
\hline Zensun (Shanghai) Sci. \& Tech. Co. Ltd. & rhErbB3-f & Recombinant human ErbB3 fragment vaccine & Phase I \\
\hline
\end{tabular}

Seshagiri said the group's findings also strengthen the case for developing bispecific antibodies that target both HER2 and ErbB3 but declined to say whether the company itself plans to develop such an antibody.

Genentech declined to disclose patent details.

Lou, K.-J. SciBX 6(22); doi:10.1038/scibx.2013.535

Published online June 6, 2013

\section{REFERENCES}

1. Jaiswal, B.S. et al. Cancer Cell; published online May 18, 2013; doi:10.1016/j.ccr.2013.04.012

Contact: Somasekar Seshagiri, Genentech, Inc., South San Francisco, Calif.

e-mail: sekar@gene.com
2. Jura, N. et al. Proc. Natl. Acad. Sci. USA 106, 21608-21613 (2009)

3. Lemmon, M.A. \& Schlessinger, J. Cell 141, 1117-1134 (2010)

4. Holbro, T. et al. Proc. Natl. Acad. Sci. USA 100, 8933-8938 (2003)

5. Pinkas-Kramarski, R. et al. EMBO J. 15, 2452-2467 (1996)

6. Sergina, N.V. et al. Nature 445, 437-441 (2007)

7. Hegde, G.V. et al. Sci. Transl. Med. 5, 171 ra18 (2013)

8. Osherovich, L. SciBX 6(7); doi:10.1038/scibx.2013.155

COMPANIES AND INSTITUTIONS MENTIONED

Broad Institute of MIT and Harvard, Cambridge, Mass.

Dana-Farber Cancer Institute, Boston, Mass.

Genentech Inc., South San Francisco, Calif.

Merrimack Pharmaceuticals Inc. (NASDAQ:MACK), Cambridge,

Mass.

Roche (SIX:ROG; OTCQX:RHHBY), Basel, Switzerland

Sanofi (Euronext:SAN; NYSE:SNY), Paris, France 